\title{
Mudança do perfil de pacientes internados em hospital secundário $100 \%$ SUS após um ano de atuação de equipe de medicina hospitalar
}

\author{
Bahlis, L.F.; Diogo, L.P.; Rohr, D.; Soares, V.S.; Waldemar, F.S.; Ernadorena, \\ J.; Wajner, A.;
}

Apresentador: André Wajner

\section{Resumo}

Introdução: O modelo de cuidados de pacientes internados utilizado pela equipe de médicos hospitalistas é pouco conhecido no Brasil, porém já está estabelecido em outros países. Este modelo fundamenta-se em cuidado integral ao paciente, observância da relação custo benefício, qualidade assistencial e satisfação do cliente, ausência de conflito de interesses da equipe assistencial, educação continuada, trabalho multidisciplinar, produção de conhecimento para gestão e produção científica. Objetivo: Descrever as características demográficas, clinicas e indicadores do hospital antes e após a implementação do serviço de medicina hospitalar. Método: É realizada a coleta dos dados de todos os pacientes internados para equipe de hospitalistas. No momento da alta, por meio de questionário impresso, funcionário treinado sob supervisão da equipe assistencial realiza a coleta. Posteriormente o questionário é digitado em banco de dados do Excel ${ }^{\circledR}$. O processo de digitação é revisado e então importado para o programa SPSS ${ }^{\circledR}$. Foi utilizado como base os pacientes internados nos dois primeiros meses de atuação (novembro e dezembro de 2013) e como comparação pacientes internados para equipe um ano depois (novembro de dezembro de 2014). Foram utilizados estatística descritiva e estatística analítica com teste qui-quadrado, teste T students e Mann Whitney. Resultados: No primeiro período, foram atendidos 190 pacientes, enquanto no segundo foram 287 (aumento de 66\%). Pacientes com escore de Charlson maior do que 3 (escore de gravidade) eram 11,6\% no período inicial, sendo de $22 \%$ no período de comparação (aumento de quase 100\% com ?0,004). A mediana de tempo de internação caiu de 5 para 4 dias, ? 0,027. Não houve diferença significativa na taxa de mortalidade. Conclusão: houve mudança significativa no perfil de pacientes clínicos após um ano de atuação da equipe de medicina hospitalar. $\mathrm{O}$ número de pacientes atendido no mesmo período de tempo foi quase o dobro, com aumento importante da complexidade dos mesmos. Entretanto, o tempo de internação diminuiu. Desta forma, os dados sugerem que a implantação do modelo de medicina hospitalar teve impacto positivo na prestação de serviços aos usuários de nosso hospital.

\section{Referência:}

Bahlis, L.F.; Diogo, L.P.; Rohr, D.; Soares, V.S.; Waldemar, F.S.; Ernadorena, J.; Wajner, A.;. Mudança do perfil de pacientes internados em hospital secundário 100\% SUS após um ano de atuação de equipe de medicina hospitalar. In: II Congresso Brasileiro de Medicina Hospitalar - II CBMH [= Blucher Medical Proceedings, vol.1, num.5] São Paulo: Editora Blucher, 2014. p.88

DOI 10.5151/medpro-II-cbmh-086 